\title{
CYBA Gene Polymorphisms and Adverse Outcomes in Acute Kidney Injury: A Prospective Cohort Study
}

\author{
Mary C. Perianayagam ${ }^{\mathrm{a}}$ Hocine Tighiouart $^{\mathrm{b}}$ \\ Caroline M. Nievergelt ${ }^{c}$ Daniel T. O'Connor ${ }^{c}$ Orfeas Liangos $^{d}$ \\ Bertrand L. Jaber ${ }^{\mathrm{a}}$ \\ a Department of Medicine, Division of Nephrology, Kidney and Dialysis Research \\ Laboratory, St. Elizabeth's Medical Center, and ' ${ }^{b}$ Biostatistics Research Center, Tufts Medical \\ Center, Boston, Mass., and ' Department of Medicine, Center for Human Genetics and

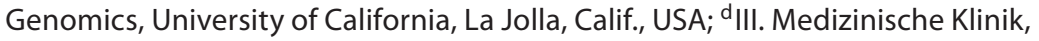 \\ Klinikum Coburg, Coburg, Germany
}

\section{Key Words}

Acute kidney injury $\cdot C Y B A \cdot$ Gene polymorphisms $\cdot$ Haplotype $\cdot$ Isoprostane $\cdot$ NADPH oxidase $\cdot$ Nitrotyrosine $\cdot \mathrm{NOX} \cdot \mathrm{p} 22^{\text {phox }}$

\begin{abstract}
Background: NADPH oxidase is an important enzyme involved in the generation of reactive oxygen species in acute kidney injury (AKI). Its key subunit, p22 ${ }^{\text {phox }}$, is encoded by the highly polymorphic CYBA gene. Methods: We examined the associations of CYBA gene polymorphisms across the CYBA locus (rs8854, rs3794624, rs4673, rs4782390, and rs1049255) with dialysis requirement or in-hospital death in 256 hospitalized adults with AKI. Dominant and haplotype multivariable logistic regression analyses were performed, adjusted for sex, race, age, and severity of illness. Results: The baseline characteristics of the patients were not different among genotype groups with the exception of a lower prevalence of sepsis and shock in the CYBA rs8854 A-allele group; a higher prevalence of shock in the CYBA rs4782390 T-allele group, and a higher APACHE II score in the CYBA rs1049255 G-allele group. The CYBA rs8854 A-allele had an adjusted odds ratio (OR) of 0.41 (95\% confidence interval, $\mathrm{Cl}, 0.18-0.96$ ) for the outcome of dialysis requirement or in-hospital death. The CYBA rs4673 T-allele and rs1049255 G-allele had unadjusted ORs of $1.69(95 \% \mathrm{Cl} 1.03-2.79)$ and $1.66(95 \% \mathrm{Cl} 1.01-2.73)$ for the composite outcome, respectively, which became non-significant after multivariable adjustment. The remain-
\end{abstract}


ing 2 polymorphisms were not associated with the outcomes of interest. Finally, the presence of the CYBA A-A-G-G haplotype (generated from rs4782390, rs4673, rs3794624, and rs8854, all in Hardy-Weinberg equilibrium) was associated with an elevated OR of 1.81 (95\% Cl 1.07-3.08) for dialysis requirement or in-hospital death, which was attenuated after multivariable adjustment (OR 1.80; 95\% Cl 0.99-3.29). Conclusion: This study identifies several polymorphisms spanning the entire CYBA gene locus and a common haplotype as risk markers for dialysis requirement or in-hospital death in patients with AKI. Additional studies are needed to validate these findings.

Copyright $\odot 2011$ S. Karger AG, Basel

\section{Introduction}

Acute kidney injury (AKI) is a common condition and is associated with an increased risk of in-hospital mortality and heightened resource consumption, including prolonged hospitalization and greater healthcare expenditures $[1,2]$. Although reactive oxygen species (ROS) have been incriminated in the pathogenesis and evolution of AKI [3-9], there is significant unexplained variability in the prediction of adverse kidney-related outcomes $[10,11]$.

In recent years, several genetic polymorphisms have been explored as potential determinants of disease severity and adverse outcomes in patients with AKI [12-18]. An important source of ROS in AKI is NADPH oxidase (NOX), an enzyme complex that primarily produces superoxide [19]. This enzyme has multiple components, including 2 transmembrane subunits (gp91 ${ }^{\text {phox }}$ and $\left.\mathrm{p} 22^{\text {phox }}\right), 3$ cytosolic subunits (p40 ${ }^{\text {phox }}, \mathrm{p} 47^{\text {phox }}$, and p67 ${ }^{\text {phox }}$ ), and a GTP-binding protein (p21).

The $\mathrm{p} 22^{\text {phox }}$ subunit is the final transporter in the chain transferring electrons from $\mathrm{NADPH}$ to molecular oxygen, and is encoded by the $\alpha$ subunit of the cytochrome $\mathrm{b}_{245}(C Y B A)$ gene, which is located on chromosome 16q24. Several polymorphisms in the CYBA gene have been described, some of which have been associated with increased [20] or decreased NOX activity [21], as well as reduced ROS generation [22, 23]. Genetic variation in the expression of this key enzyme might account for the interindividual variability observed in the manifestation of AKI. The aim of the present study was to examine whether 5 key polymorphisms in the CYBA gene locus and corresponding haplotypes are associated with disease severity and adverse outcome in hospitalized AKI patients.

\section{Patients and Methods}

\section{Study Design and Participants}

This was a prospective cohort study of hospitalized AKI patients, which was conducted at two tertiary care hospitals (Boston, Mass., USA). All consecutive hospitalized adults with AKI, in whom nephrology consultation was requested, were eligible for enrollment. AKI was defined according to the criteria by Hou et al. [24], i.e. a rise in serum creatinine by $0.5,1.0$, or $1.5 \mathrm{mg} / \mathrm{dl}$ from a baseline level $\leq 1.9,2.0-4.9$, or $\geq 5.0 \mathrm{mg} / \mathrm{dl}$, respectively. This definition was adopted prior to the development of the more recent AKI network consensus definition [25]. However, we used this classification to categorize AKI stages.

Exclusion criteria were age $<18$ years, pregnancy, long-term dialysis, organ transplantation within the prior year, and presence of acute obstructive uropathy. Institutional review board approval was granted, and written informed consent was obtained from all participants or next of kin. 


\section{Data Collection}

Hospital records were reviewed prospectively to retrieve information on baseline demographic characteristics, coexisting conditions, and kidney-related variables, including serial serum creatinine values and 24-hour urine output at enrollment. Sepsis was ascertained using the systemic inflammatory response syndrome criteria [26], and two severity-of-illness scores were calculated, the APACHE II (Acute Physiology and Chronic Health Evaluation) score [27] and the MOF (Multiple Organ Failure) score [28]. Preexisting chronic kidney disease was defined on the basis of a baseline estimated glomerular filtration rate $<60 \mathrm{ml} /$ $\min / 1.73 \mathrm{~m}^{2}$, which was calculated using the MDRD (Modification of Diet in Renal Disease) equation [29].

\section{Blood and Urine Sampling}

At enrollment, EDTA-anticoagulated whole blood and urine were collected. Plasma was separated, and the remaining blood was aliquoted for subsequent DNA extraction. Either freshly voided urine or urine from the access port of a Foley catheter was obtained, kept on ice and processed within $30 \mathrm{~min}$ after collection. Samples were centrifuged for $10 \mathrm{~min}$ at $3,000 \mathrm{rpm}$, treated with a protease inhibitor cocktail (Complete Mini; Roche Diagnostics, Mannheim, Germany) and then aliquoted. All samples were stored at $-80^{\circ} \mathrm{C}$.

\section{Selection Criteria and TaqMan Genotyping Analyses}

To obtain a comprehensive representation of the genetic variability in the CYBA gene locus (reference sequence GeneBank accession No. NM 000101.2), we selected the genetic variants according to several criteria, including published reports on investigated clinical and functional associations; variants with at least $10 \%$ minor allele frequency, and variants preferentially located in the promoter, coding, non-coding, and untranslated regions (UTR). Through this careful selection process, we identified the following 5 polymorphisms of interest in the CYBA gene locus: promoter $-1442(\mathrm{G} \rightarrow \mathrm{A}$, reference single nucleotide polymorphism, refSNP, rs8854), intron $1+383(\mathrm{G} \rightarrow \mathrm{A}$, refSNP rs3794624), exon $4+242(\mathrm{C} \rightarrow \mathrm{T}$, refSNP rs4673), and 3'-UTR $+8897(\mathrm{~A} \rightarrow \mathrm{T}$, refSNP rs4782390), and $+640(\mathrm{~A} \rightarrow \mathrm{G}$, refSNP rs1049255).

Genomic DNA was prepared from whole blood leukocytes using the QiAmp DNA blood kit (Qiagen, Valencia, Calif., USA). DNA samples were then genotyped by combining the TaqMan universal PCR master mix with the TaqMan SNP genotyping assay into a 384-well plate using the Applied Biosystems 7900HT fast real-time PCR system (Applied Biosystems, Foster City, Calif., USA) according to a standardized protocol. Resulting sequences were analyzed by the SNP software (SDS version 2.2), which uses an advanced multi-component algorithm to calculate distinct allele/marker signal contributions from fluorescence measurements for each sample well during the assay plate read with the SNP auto-caller. The SNP auto-caller automatically determines sample genotypes and generates a cluster plot to better visualize data across samples. Pairwise patterns of linkage disequilibrium (LD) across the CYBA gene locus were visualized by Haploview (www.broadinstitute.org), plotting LD as the $\mathrm{D}^{\prime}$ parameter (scaled from 0 to 100), and excluding the polymorphism(s) that did not meet the Hardy-Weinberg equilibrium. Haplotypes were imputed from the CYBA polymorphism diploid genotypes using PLINK (http://pngu.mgh.harvard.edu/ purcell/plink/). The most frequent haplotype across the 4 polymorphisms in Hardy-Weinberg equilibrium (rs4782390, rs4673, rs3794624, and rs8854) was A-A-G-G, and was expressed as the number of chromosomal copies of the haplotype $(0,1$, and 2$)$ for each patient.

\section{Measurement of Markers of Oxidative Stress}

To evaluate whether the CYBA gene polymorphisms were associated with markers of oxidative stress, we measured plasma nitrotyrosine (a byproduct of superoxide and nitric 
oxide generation) and urinary $15-\mathrm{F}_{2 \mathrm{t}}$-isoprostane (a marker of lipid peroxidation). All measurements were performed in duplicate. In brief, plasma nitrotyrosine was measured by sandwich ELISA (OxisResearch, Foster City, Calif., USA; results are reported in nM). Urinary $15-\mathrm{F}_{2 \mathrm{t}}$-isoprostane was measured by competitive ELISA (Northwest Life Science Specialties, LLC, Vancouver, Wash., USA). The results were normalized to urinary creatinine (expressed as $\mathrm{ng} / \mathrm{mg}$ of creatinine).

\section{Outcome Measures}

Our primary outcome of interest was the composite of dialysis requirement or in-hospital death. Our secondary outcome was the composite of dialysis requirement, assisted mechanical ventilation, or in-hospital death.

\section{Statistical Analyses}

The genotype frequencies were tested for Hardy-Weinberg equilibrium using a standard $\chi^{2}$ test for any deviation in the observed frequencies. Comparisons between genotype groups were made by the Kruskal-Wallis test and the two-tailed Mann-Whitney test for continuous variables, and the $\chi^{2}$ or Fisher exact test for categorical variables. Results are expressed as means (SD), medians, or percentages.

Using dominant genetic models (i.e., one or two copies of the minor allele), multivariable logistic regression analyses were performed to examine the association of each CYBA gene polymorphism with the aforementioned primary and secondary endpoints. All models were adjusted for sex, race, and age (model 1), or sex, race, and the APACHE II score (model 2). Sepsis was added as a covariate in sensitivity analyses. The results of the logistic regression analyses are displayed as odds ratio (OR) with $95 \%$ confidence interval (CI). Using a stepwise forward and backward selection process, logistic regression analyses were also performed to identify potential haplotypes that are associated with the outcomes of interest. Only CYBA gene polymorphisms that were associated with the primary composite outcome on univariate analyses, using a value of $\mathrm{p}<0.1$, were selected for the haplotype analyses.

All statistical analyses were performed using SAS software (version 9.1; SAS Institute, Cary, N.C., USA). Differences were considered statistically significant at $\mathrm{p}<0.05$.

\section{Results}

\section{Characteristics of the AKI Cohort Stratified by CYBA Gene Polymorphisms}

Between November 2003 and February 2010, a total of 264 participants were enrolled in the study, of which 2 were excluded due to study ineligibility and lack of genomic DNA sampling. The present analysis includes 262 participants who underwent genotyping analyses. At enrollment, mean age was 66 years, $53 \%$ were men, and $91 \%$ were of white ethnicity. Mean APACHE II score was 20 , and $73 \%$ were in the intensive care unit. The majority of the subjects had severe AKI, as defined by the AKI network criteria, with 136 (52\%) fulfilling stage-3 AKI. In-hospital mortality was $22 \%, 24 \%$ required mechanical ventilation, $39 \%$ required dialysis, and $47 \%$ experienced the composite outcome of dialysis requirement or in-hospital death.

Genotyping was successfully performed on 256-262 subjects. As shown in table 1, only 1 of the 5 CYBA gene polymorphisms (rs8854) had a minor allele frequency $<10 \%$. Tests for Hardy-Weinberg equilibrium revealed no deviation from expected frequencies with the exception of the CYBA rs1049255 polymorphism.

The characteristics of the AKI cohort stratified by the 5 CYBA gene polymorphisms are shown in table 2 . In brief, overall patient demographics, co-morbidities and disease severity 
Table 1. Observed and expected distribution of CYBA gene polymorphisms in the AKI cohort

\begin{tabular}{|c|c|c|c|c|c|c|c|}
\hline \multirow[t]{2}{*}{ Locus } & \multirow{2}{*}{$\begin{array}{l}\text { RefSNP } \\
\text { dbSNP } \\
\text { No. }\end{array}$} & \multirow[t]{2}{*}{ SNP } & \multirow[t]{2}{*}{ Domain } & \multirow{2}{*}{$\begin{array}{l}\text { Samples } \\
\text { successfully } \\
\text { genotyped, } n\end{array}$} & \multirow[t]{2}{*}{$\begin{array}{l}\text { Variant allele } \\
\text { (frequency) }\end{array}$} & \multicolumn{2}{|c|}{$\begin{array}{l}\text { Hardy-Weinberg } \\
\text { equilibrium }\end{array}$} \\
\hline & & & & & & $x^{2}$ & $\mathrm{p}$ value \\
\hline CYBA & rs8854 & $-1442 \mathrm{G} \rightarrow \mathrm{A}$ & promoter & 262 & $\mathrm{~A}(7 \%)$ & 2.22 & 0.14 \\
\hline CYBA & rs3794624 & $383 \mathrm{G} \rightarrow \mathrm{A}$ & intron 1 & 257 & A $(33 \%)$ & 0.19 & 0.66 \\
\hline CYBA & rs4673 & $242 \mathrm{C} \rightarrow \mathrm{T}$ & $\begin{array}{l}\text { exon } 4 \\
\text { (Tyr }{ }^{72} \text { His) }\end{array}$ & 262 & $\mathrm{~T}(38 \%)$ & 1.71 & 0.19 \\
\hline CYBA & rs 4782390 & $8897 \mathrm{~A} \rightarrow \mathrm{T}$ & $3^{\prime}$-UTR & 260 & $\mathrm{~T}(32 \%)$ & 0.27 & 0.60 \\
\hline CYBA & rs1049255 & $640 \mathrm{~A} \rightarrow \mathrm{G}$ & 3'-UTR & 256 & G (36\%) & 1.09 & $<0.0001$ \\
\hline
\end{tabular}

Table 2. Enrollment characteristics of the AKI cohort according to the 5 CYBA gene polymorphisms

\begin{tabular}{|c|c|c|c|c|c|c|c|c|c|c|c|c|c|c|c|}
\hline \multirow[t]{2}{*}{ Characteristic } & \multicolumn{2}{|c|}{$\begin{array}{l}\text { rs8854 } \\
\text { genotypes }\end{array}$} & \multirow[t]{2}{*}{$\begin{array}{l}\mathrm{p} \\
\text { value }\end{array}$} & \multicolumn{2}{|c|}{$\begin{array}{l}\text { rs3794624 } \\
\text { genotypes }\end{array}$} & \multirow[t]{2}{*}{$\begin{array}{l}\mathrm{p} \\
\text { value }\end{array}$} & \multicolumn{2}{|c|}{$\begin{array}{l}\text { rs } 4673 \\
\text { genotypes }\end{array}$} & \multirow[t]{2}{*}{$\begin{array}{l}\mathrm{p} \\
\text { value }\end{array}$} & \multicolumn{2}{|c|}{$\begin{array}{l}\text { rs4782390 } \\
\text { genotypes }\end{array}$} & \multirow[t]{2}{*}{$\begin{array}{l}\mathrm{p} \\
\text { value }\end{array}$} & \multicolumn{2}{|l|}{$\begin{array}{l}\text { rs1049255 } \\
\text { genotypes }\end{array}$} & \multirow[t]{2}{*}{$\begin{array}{l}\mathrm{p} \\
\text { value }\end{array}$} \\
\hline & $\begin{array}{l}\text { GG } \\
227\end{array}$ & $\begin{array}{l}\text { GA/AA } \\
35\end{array}$ & & $\begin{array}{l}\text { GG } \\
118\end{array}$ & $\begin{array}{l}\text { GA/AA } \\
139\end{array}$ & & $\begin{array}{l}\text { CC } \\
107\end{array}$ & $\begin{array}{l}\mathrm{CT} / \mathrm{TT} \\
155\end{array}$ & & $\begin{array}{l}\text { AA } \\
123\end{array}$ & $\begin{array}{l}\mathrm{AT} / \mathrm{TT} \\
137\end{array}$ & & $\begin{array}{l}\text { AA } \\
143\end{array}$ & $\begin{array}{l}\mathrm{AG} / \mathrm{GG} \\
113\end{array}$ & \\
\hline Age, years & $66(15)$ & $66(18)$ & 0.81 & $67(15)$ & $65(16)$ & 0.38 & $65(16)$ & $67(15)$ & 0.32 & $66(15)$ & $65(16)$ & 0.61 & $65(15)$ & $67(16)$ & 0.53 \\
\hline Males, \% & 52 & 60 & 0.35 & 52 & 54 & 0.72 & 50 & 55 & 0.40 & 55 & 50 & 0.36 & 54 & 52 & 0.80 \\
\hline Race, \% & & & 0.83 & & & 0.49 & & & 0.11 & & & 0.003 & & & 0.006 \\
\hline White & 90 & 91 & & 90 & 91 & & 87 & 93 & & 85 & 96 & & 95 & 85 & \\
\hline Black & 7 & 6 & & 9 & 6 & & 8 & 6 & & 12 & 2 & & 3 & 12 & \\
\hline Other & 3 & 3 & & 2 & 3 & & 5 & 1 & & 3 & 2 & & 2 & 3 & \\
\hline \multicolumn{3}{|l|}{$\begin{array}{l}\text { Contributing cause } \\
\text { of AKI, \% }\end{array}$} & 0.35 & & & 0.46 & & & 0.34 & & & 0.89 & & & 0.66 \\
\hline Ischemic & 29 & 20 & & 25 & 30 & & 26 & 30 & & 26 & 30 & & 26 & 32 & \\
\hline Nephrotoxic & 15 & 23 & & 20 & 13 & & 15 & 16 & & 17 & 15 & & 17 & 15 & \\
\hline Septic & 9 & 11 & & 11 & 8 & & 6 & 12 & & 10 & 9 & & 8 & 10 & \\
\hline Multifactorial/other & 33 & 40 & & 32 & 36 & & 40 & 29 & & 33 & 34 & & 37 & 30 & \\
\hline \multicolumn{16}{|c|}{ Coexisting conditions, $\%$} \\
\hline $\mathrm{DM}$ & 45 & 43 & 0.86 & 46 & 43 & 0.68 & 44 & 45 & 0.93 & 40 & 48 & 0.18 & 48 & 42 & 0.34 \\
\hline Heart failure & 17 & 9 & 0.20 & 16 & 16 & 0.95 & 14 & 17 & 0.46 & 20 & 13 & 0.16 & 15 & 18 & 0.62 \\
\hline Cirrhosis & 7 & 11 & 0.31 & 9 & 5 & 0.26 & 9 & 7 & 0.53 & 7 & 8 & 0.65 & 8 & 4 & 0.12 \\
\hline CLD & 19 & 14 & 0.51 & 15 & 21 & 0.25 & 21 & 17 & 0.44 & 21 & 16 & 0.29 & 19 & 18 & 0.81 \\
\hline CKD & 68 & 69 & 0.94 & 69 & 68 & 0.87 & 70 & 65 & 0.52 & 71 & 66 & 0.43 & 69 & 65 & 0.48 \\
\hline APACHE II score & $20(7)$ & $18(5)$ & 0.176 & $20(6)$ & $20(7)$ & 0.84 & $19(6)$ & $20(7)$ & 0.21 & $20(7)$ & $19(6)$ & 0.23 & $19(6)$ & $21(7)$ & 0.01 \\
\hline Sepsis, \% & 45 & 26 & 0.03 & 44 & 42 & 0.81 & 37 & 47 & 0.09 & 42 & 45 & 0.62 & 43 & 43 & 0.95 \\
\hline Shock, \% & 30 & 11 & 0.02 & 24 & 31 & 0.20 & 24 & 30 & 0.29 & 22 & 34 & 0.04 & 30 & 25 & 0.35 \\
\hline \multicolumn{16}{|c|}{ Serum creatinine, $m g / d l$} \\
\hline Baseline value & $1.6(0.8)$ & $1.4(0.5)$ & 0.37 & $1.6(0.8)$ & $1.5(0.6)$ & 0.82 & $1.6(0.6)$ & $1.5(0.8)$ & 0.56 & $1.6(0.8)$ & $1.5(0.6)$ & 0.07 & $1.5(0.6)$ & $1.6(0.8)$ & 0.53 \\
\hline Enrollment value & $3.6(1.8)$ & $3.5(1.4)$ & 0.96 & $3.7(1.9)$ & $3.5(1.6)$ & 0.46 & $3.6(1.7)$ & $3.5(1.8)$ & 0.55 & $3.7(1.8)$ & $3.4(1.7)$ & 0.20 & $3.4(1.6)$ & $3.6(1.9)$ & 0.36 \\
\hline Peak & $4.4(2.7)$ & $4.1(1.8)$ & 0.61 & $4.7(3.2)$ & $4.1(1.9)$ & 0.08 & $4.3(2.1)$ & $4.4(2.9)$ & 0.65 & $4.5(3.0)$ & $4.2(2.2)$ & 0.34 & $4.4(3.0)$ & $4.3(2.0)$ & 0.72 \\
\hline Discharge & $2.5(1.7)$ & $2.3(1.6)$ & 0.37 & $2.5(1.8)$ & $2.5(1.7)$ & 0.89 & $2.5(1.6)$ & $2.5(1.8)$ & 0.85 & $2.7(1.9)$ & $2.4(1.5)$ & 0.12 & $2.4(1.7)$ & $2.7(1.7)$ & 0.18 \\
\hline Urine output, $l /$ day & $1.2(1.1)$ & $1.5(1.2)$ & 0.25 & $1.2(1.0)$ & $1.3(1.2)$ & 0.69 & $1.3(1.2)$ & $1.2(1.0)$ & 0.33 & $1.4(1.1)$ & $1.2(1.0)$ & 0.12 & $1.2(1.0)$ & $1.4(1.1)$ & 0.39 \\
\hline $\begin{array}{l}\text { AKI stage at } \\
\text { enrollment, } \%\end{array}$ & & & 0.47 & & & 0.11 & & & 0.41 & & & 0.68 & & & 0.87 \\
\hline Stage 1 & 43 & 43 & & 36 & 49 & & 43 & 43 & & 41 & 46 & & 44 & 42 & \\
\hline Stage 2 & 4 & 9 & & 5 & 4 & & 7 & 3 & & 45 & 5 & & 5 & 4 & \\
\hline Stage 3 & 53 & 49 & & 59 & 47 & & 50 & 54 & & 55 & 49 & & 51 & 54 & \\
\hline \multicolumn{16}{|c|}{ Oxidative stress markers } \\
\hline $\begin{array}{l}\text { Plasma nitro- } \\
\text { tyrosine, nM }\end{array}$ & $\begin{array}{l}12 \\
(9,23)\end{array}$ & $\begin{array}{l}11 \\
(10,24)\end{array}$ & 0.29 & $\begin{array}{l}12 \\
(9,24)\end{array}$ & $\begin{array}{l}12 \\
(9,22)\end{array}$ & 0.45 & $\begin{array}{l}12 \\
(9,21)\end{array}$ & $\begin{array}{l}12 \\
(9,24)\end{array}$ & 0.38 & $\begin{array}{l}12 \\
(9,22)\end{array}$ & $\begin{array}{l}12 \\
(8,23)\end{array}$ & 0.30 & $\begin{array}{l}12 \\
(9,23)\end{array}$ & $\begin{array}{l}12 \\
(9,22)\end{array}$ & 0.21 \\
\hline $\begin{array}{l}\text { Urinary } 15-\mathrm{F}_{2 \mathrm{t}} \text {-iso- } \\
\text { prostane, } \mathrm{ng} / \mathrm{mg}\end{array}$ & $\begin{array}{l}1.1 \\
(0.6,2.2)\end{array}$ & $\begin{array}{l}1.1 \\
(0.6,4.0)\end{array}$ & 0.42 & $\begin{array}{l}1.1 \\
(0.6,2.8)\end{array}$ & $\begin{array}{l}1.1 \\
(0.6,2.0)\end{array}$ & 0.49 & $\begin{array}{l}1.2 \\
(0.6,2.6)\end{array}$ & $\begin{array}{l}1.0 \\
(0.6,2.0)\end{array}$ & 0.56 & $\begin{array}{l}1.0 \\
(0.5,2.0)\end{array}$ & $\begin{array}{l}1.2 \\
(0.6,2.4)\end{array}$ & 0.87 & $\begin{array}{l}1.2 \\
(0.7,2.7)\end{array}$ & $\begin{array}{l}0.9 \\
(0.5,1.7)\end{array}$ & 0.73 \\
\hline
\end{tabular}

$\mathrm{CKD}=$ Chronic kidney disease; $\mathrm{CLD}=$ chronic lung disease; $\mathrm{DM}=$ diabetes mellitus. Continuous variables are presented as means (SD) or medians (25th, 75 th percentile), and categorical variables as percentages. Missing genotyping data: $r s 3794624(n=5), \operatorname{rs} 4782390(n=2)$, and $r s 1049255(n=6)$. 
Fig. 1. Dialysis requirement or in-hospital death in the AKI cohort stratified by the $C Y B A$ rs8854 genotypes and APACHE II score tertiles. ${ }^{*} \mathrm{p}=0.006$ vs. GG genotype in the APACHE II score upper tertile.

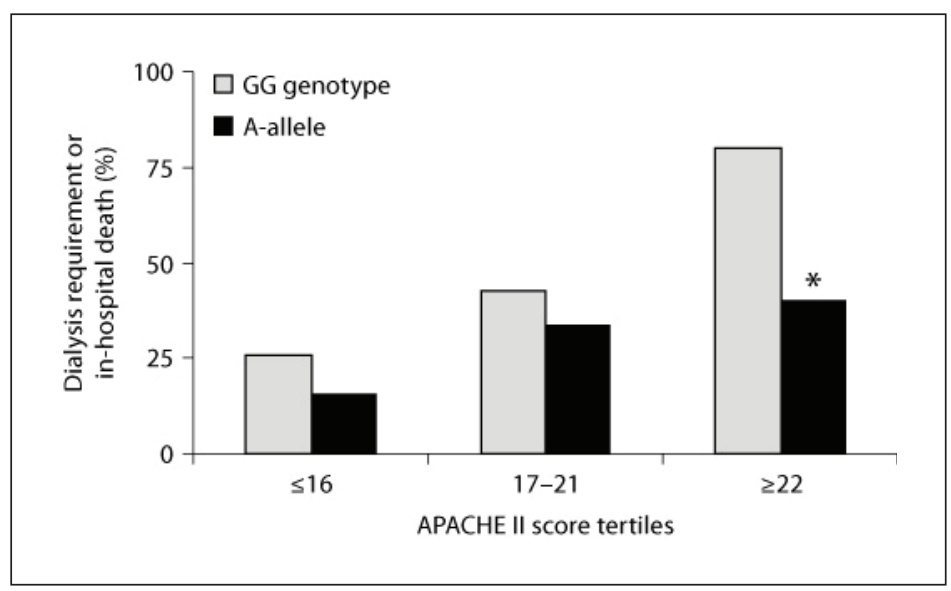

measures did not significantly differ across genotypes, with a few notable exceptions. The CYBA rs8854 minor A-allele (GA/AA genotype) group had a lower prevalence of sepsis ( $\mathrm{p}=$ $0.03)$ and shock $(\mathrm{p}=0.02)$ compared with the GG genotype group; the CYBA rs4782390 minor T-allele (AT/TT genotype) group had a higher prevalence of shock $(\mathrm{p}=0.04)$ compared with the AA genotype group, and the CYBA rs1049255 minor G-allele (AG/GG genotype) group had a higher APACHE II score $(\mathrm{p}=0.01)$ compared with the AA genotype group. A genotype-phenotype association was not demonstrable between individual CYBA gene polymorphisms and 2 markers of oxidative stress, plasma nitrotyrosine and urinary $15-\mathrm{F}_{2 \mathrm{t}}$-isoprostane levels (table 2).

\section{CYBA Gene Polymorphisms and Adverse Outcomes}

Compared with the GG genotype group, the CYBA rs8854 A-allele group experienced less dialysis requirement or in-hospital death ( 50 vs. $29 \%$; $p=0.02$ ). Figure 1 displays the outcome of dialysis requirement or in-hospital death stratified by CYBA rs8854 genotypes and APACHE II score tertiles. The outcome of dialysis requirement or in-hospital death was overall less frequent among A-allele carriers within each APACHE II score tertile but within the highest APACHE II score tertile, the composite outcome was significantly lower in the CYBA rs8854 A-allele compared with the GG genotype group (40 vs. $80 \%$; $\mathrm{p}=0.006$ ).

As shown in table 3, the CYBA rs8854 A-allele group had an unadjusted OR of 0.40 (95\% CI 0.19-0.88) for the outcome of dialysis requirement or in-hospital death compared with the GG genotype group. This association persisted after adjustment for sex, race, and age (OR 0.39; 95\% CI 0.18-0.85), as well as sex, race, and APACHE II score (OR 0.41; 95\% CI 0.180.96). A similar association was observed after adjustment for sex, race, APACHE II score, and sepsis (data not shown). The CYBA rs8854 A-allele group was also associated with the secondary outcome of dialysis requirement, assisted mechanical ventilation, or in-hospital death after adjustment for sex, race, and age (OR 0.42; 95\% CI 0.20-0.89), as well as sex, race and APACHE II score (OR 0.43; 95\% CI 0.18-0.99).

By contrast, the CYBA rs4673 T-allele and rs1049255 G-allele group had an unadjusted OR of 1.69 (95\% CI 1.03-2.79) and 1.66 (95\% CI 1.01-2.73) for the outcome of dialysis requirement or in-hospital death compared with the CC genotype and AA genotype group, respectively (table 3). These associations were attenuated after adjustment for sex, race, and age, but became non-significant once adjusted for the APACHE II score. There was not any association between the CYBA rs3794624 or rs 4782390 polymorphism and the primary and secondary composite outcomes (table 3). 
Table 3. Association of the 5 CYBA gene polymorphisms with adverse outcomes in the AKI cohort

\begin{tabular}{|c|c|c|c|c|c|c|}
\hline \multirow[t]{2}{*}{ Predicted variable } & \multicolumn{3}{|c|}{$\begin{array}{l}\text { Dialysis requirement or in-hospital } \\
\text { death }\end{array}$} & \multicolumn{3}{|c|}{$\begin{array}{l}\text { Dialysis requirement, mechanical } \\
\text { ventilation, or in-hospital death }\end{array}$} \\
\hline & OR & $95 \% \mathrm{CI}$ & $\mathrm{p}$ value & OR & $95 \% \mathrm{CI}$ & $\mathrm{p}$ value \\
\hline \multicolumn{7}{|l|}{ rs8854 (A-allele vs. $G / G)$} \\
\hline Unadjusted & 0.40 & $0.19,0.88$ & 0.02 & 0.43 & $0.20,0.90$ & 0.03 \\
\hline Model 1 & 0.39 & $0.18,0.85$ & 0.02 & 0.42 & $0.20,0.89$ & 0.02 \\
\hline Model 2 & 0.41 & $0.18,0.96$ & 0.04 & 0.43 & $0.18,0.99$ & 0.05 \\
\hline \multicolumn{7}{|c|}{ rs3794624 (A-allele vs. $G / G)$} \\
\hline Unadjusted & 0.92 & $0.56,1.50$ & 0.73 & 1.07 & $0.65,1.75$ & 0.79 \\
\hline Model 1 & 0.91 & $0.55,1.49$ & 0.71 & 1.06 & $0.65,1.73$ & 0.82 \\
\hline Model 2 & 0.93 & $0.54,1.62$ & 0.80 & 1.17 & $0.66,2.07$ & 0.59 \\
\hline \multicolumn{7}{|l|}{ rs4673 (T-allele vs. C/C) } \\
\hline Unadjusted & 1.69 & $1.03,2.79$ & 0.04 & 1.37 & $0.83,2.24$ & 0.21 \\
\hline Model 1 & 1.66 & $1.00,2.74$ & 0.05 & 1.35 & $0.82,2.23$ & 0.24 \\
\hline Model 2 & 1.53 & $0.88,2.68$ & 0.13 & 1.19 & $0.67,2.11$ & 0.55 \\
\hline \multicolumn{7}{|c|}{ rs4782390 (T-allele vs. A/A) } \\
\hline Unadjusted & 0.84 & $0.52,1.37$ & 0.45 & 1.12 & $0.69,1.82$ & 0.65 \\
\hline Model 1 & 0.82 & $0.49,1.35$ & 0.43 & 1.07 & $0.65,1.77$ & 0.78 \\
\hline Model 2 & 0.92 & $0.53,1.60$ & 0.77 & 1.37 & $0.77,2.45$ & 0.29 \\
\hline \multicolumn{7}{|c|}{ rs1049255 (G-allele vs. A/A) } \\
\hline Unadjusted & 1.66 & $1.01,2.73$ & 0.05 & 1.44 & $0.88,2.37$ & 0.15 \\
\hline Model 1 & 1.74 & $1.04,2.89$ & 0.03 & 1.51 & $0.91,2.51$ & 0.11 \\
\hline Model 2 & 1.36 & $0.77,2.41$ & 0.29 & 1.08 & $0.60,1.96$ & 0.79 \\
\hline \multicolumn{7}{|l|}{$A-A-G-G$ haplotype ${ }^{a}$} \\
\hline Unadjusted & & & 0.07 & & & 0.09 \\
\hline 1 copy (vs. none) & 1.81 & $1.07,3.08$ & 0.03 & 1.58 & $0.93,2.69$ & 0.09 \\
\hline 2 copies (vs. none) & 1.06 & $0.50,2.23$ & 0.88 & 0.77 & $0.37,1.61$ & 0.48 \\
\hline Model 1 & & & 0.09 & & & 0.12 \\
\hline 1 copy (vs. none) & 1.76 & $1.03,3.01$ & 0.04 & 1.55 & $0.91,2.66$ & 0.11 \\
\hline 2 copies (vs. none) & 1.06 & $0.50,2.24$ & 0.88 & 0.78 & $0.37,1.64$ & 0.50 \\
\hline Model 2 & & & 0.09 & & & 0.05 \\
\hline 1 copy (vs. none) & 1.80 & $0.99,3.29$ & 0.05 & 1.61 & $0.86,3.01$ & 0.13 \\
\hline 2 copies (vs. none) & 0.87 & $0.38,2.00$ & 0.75 & 0.54 & $0.23,1.28$ & 0.16 \\
\hline
\end{tabular}

Model 1 is adjusted for sex, race, and age; model 2 is adjusted for sex, race, and APACHE II score.

a The haplotype was generated from the CYBA rs4782390, rs4673, rs3794624, and rs8854 polymorphisms that were in Hardy-Weinberg equilibrium.

\section{CYBA Haplotypes and Adverse Outcomes}

We next generated a Haploview plot on 4 CYBA gene polymorphisms after exclusion of rs1049255, which did not fulfill Hardy-Weinberg equilibrium. Figure 2 displays the LD plot at the CYBA gene locus with representation of the 4 variants analyzed in our study cohort. The LD plot revealed substantial correlation (as defined by the $\mathrm{D}^{\prime}$ parameter) across the $\sim 8$-kbp human CYBA locus, with the rs8854 and rs4673 polymorphisms displaying the highest correlation, as evidenced by a $\mathrm{D}^{\prime}$ parameter of 85 (on a scale of $0-100$ ).

Finally, we conducted haplotype analyses after excluding the polymorphism that did not fulfill the Hardy-Weinberg equilibrium (rs1049255). The most frequent haplotype was A-AG-G estimated on 186 chromosomes with a frequency of $56.5 \%$. As shown in table 3, the 
Fig. 2. $C Y B A$ gene locus Haploview plot in the AKI cohort. The Haploview plot was generated on 4 CYBA gene polymorphisms after exclusion of rs1049255, which did not fulfill the Hardy-Weinberg equilibrium. The plot illustrates pairwise LD between all polymorphisms based on $\mathrm{D}^{\prime}$ values. The darker a rhombus appears, the higher the LD is between the respective polymorphisms.

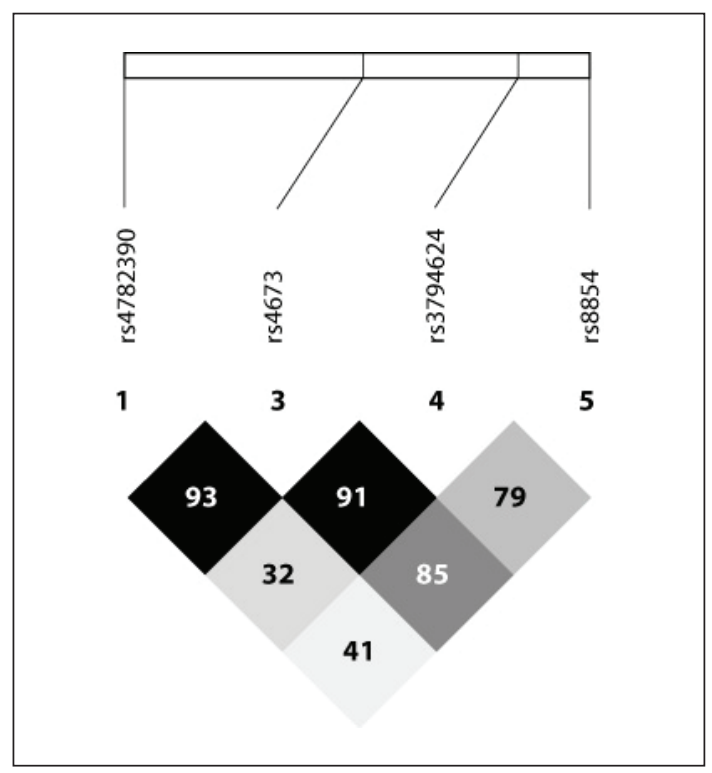

presence of one copy of this common haplotype was associated with an OR of 1.81 (95\% CI 1.07-3.08) for the outcome of dialysis requirement or in-hospital death, which persisted after adjustment for sex, race, and age (OR 1.76; 95\% CI 1.03-3.01), but was attenuated after adjustment for sex, race, and APACHE II score (OR 1.80; 95\% CI 0.99-3.29). The haplotype A-AG-G association was directionally consistent with that observed for the CYBA rs4673 polymorphism. Of note, however, there was no association with the presence of two copies of the CYBA A-A-G-G haplotype.

\section{Discussion}

In the present study, we examined the relationship of 5 polymorphisms in the CYBA gene locus located in the promoter (rs8854), intron-1 (rs3794624), exon-4 (rs4673), and 3'-UTR (rs4782390 and rs1049255) regions, with adverse clinical outcomes in a large cohort of hospitalized patients with AKI. The observed and expected genotype frequencies were not significantly different, with the exception of CYBA rs1049255, which did not fulfill HardyWeinberg equilibrium. Although the overall population was $91 \%$ white, there were no race, sex, or age differences within genotype groups with the exception of CYBA rs4782390 and rs1049255, which displayed race differences in allele frequencies. There was no demonstrable genotype-phenotype association between the 5 CYBA gene polymorphisms and the two selected markers of oxidative stress, plasma nitrotyrosine and urinary $15-\mathrm{F}_{2 \mathrm{t}}$-isoprostane levels. The CYBA rs8854 A-allele group experienced a lower requirement for the primary composite outcome of dialysis requirement or in-hospital death even among patients with the highest APACHE II score. After adjustment for sex, race, and APACHE II score, the CYBA rs8854 A-allele group also experienced lower odds for this adverse outcome as well as for the secondary composite of dialysis requirement, assisted mechanical ventilation or in-hospital death. By contrast, the CYBA rs4673 T-allele and rs1049255 G-allele groups had higher unadjusted odds for dialysis requirement or in-hospital death, which became non-significant once adjusted for the APACHE II score. We found no association between the CYBA rs3794624 or rs 4782390 polymorphisms and the two outcomes of interest. Finally, we identi- 
fied a common haplotype (generated from the CYBA rs4782390, rs4673, rs3794624, and rs 8854 polymorphisms) whereby the presence of a single copy, not 2 copies, was associated with higher odds for the primary outcome.

NADPH oxidase is a key enzyme that catalyzes the production of superoxide, mediating the downstream generation and injurious effects of ROS. This enzyme is highly expressed in neutrophils and endothelial cells [30] and possesses several subunits, including the p22 $2^{\text {phox }}$ subunit, which serves as the final transporter transferring an electron from NADPH to molecular oxygen. This key electron transfer protein is encoded by the CYBA gene. Given its importance in mediating oxidative stress-mediated cellular injury in response to ischemic and toxic kidney injury, one might anticipate that polymorphisms disrupting the function or expression of the NOX p22 $2^{\text {phox }}$ subunit would alter oxidative stress-mediated cellular responses in AKI. Several polymorphisms have been described in the CYBA gene that are variably linked to measures of oxidative stress, including the CYBA rs1049255 (3'-UTR) polymorphism, which has been associated with lower mRNA and protein expression and reduced NOX activity [22, 23, 31, 32], the CYBA rs 4673 ( $\mathrm{Tyr}^{72} \mathrm{His}$, exon 4 ) polymorphism (associated with reduced NOX activity [21]); the CYBA rs9932581 (not studied here) polymorphism (linked to higher promoter activity [32] and increased NOX activity [20]), and the CYBA rs8854 (upstream, promoter) polymorphism (not linked to a change in NOX activity [33]). In recent years, the relationship between genetic variability in the CYBA gene and disease has become a topic of interest. Indeed, genetic studies of cardiovascular disease examining the influence of these polymorphisms have yielded conflicting results. Specifically, the CYBA rs1049255 (3'-UTR) polymorphism was linked to increased disease susceptibility; the CYBA rs4673 (Tyr ${ }^{72} \mathrm{His}$ ) and rs 9932581 polymorphisms to decreased disease susceptibility [34, 35], and the rs4673 polymorphism to disease progression [36]. Genetic studies of kidney disease have shown a protective effect of the CYBA rs4673 polymorphism against the development of chronic kidney failure [37], and in a previously reported subgroup of the present study cohort, we found the rs4673 polymorphism to be associated with higher odds for dialysis requirement or in-hospital death [13]. In the present study, the effect estimate of this polymorphism was in the same direction but was attenuated in the adjusted analyses.

In the present study, the potential mechanisms underlying the harmful association of the common CYBA A-A-G-G haplotype with the composite of dialysis requirement or inhospital death are unknown. We propose that the worse outcomes observed amongst carriers of this haplotype might in part be due to the increased generation of ROS by NOX residing in neutrophils and endothelial cells, resulting in more extensive organ injury. However, this hypothesis requires further study.

To our knowledge, this is the first comprehensive study testing the comprehensive hypothesis of whether 5 representative polymorphisms spanning the entire CYBA gene locus associate with clinical outcomes in patients with AKI. The heterogeneity of our cohort was offset by the selective inclusion of subjects with more advanced AKI requiring formal nephrology consultation. Although sizeable, our cohort was relatively small for genetic epidemiological studies, but $91 \%$ of the study cohort were white, reducing the potential impact of race and ethnicity on genotype prevalence. Although we found some ethnic differences in allele frequencies among the CYBA rs4782390 and rs1049255 genotypes, when the analyses were adjusted for race/ethnicity, the point estimates were not significantly altered. The use of the APACHE II score as a covariate to reflect the severity of illness strengthens the plausibility of our results. Finally, our composite endpoints were chosen to account for survival bias when dialysis requirement and assisted mechanical ventilation are being assessed as outcome measures.

The present study suffers from several limitations. First, the CYBA rs1049255 polymorphism did not fulfill the Hardy-Weinberg equilibrium. A similar deviation has previously 
been noted for the CYBA rs8854 polymorphism [33], and might in part be due to our relatively modest sample size or natural selection. A likely explanation of Hardy-Weinberg equilibrium deviation is combining two biogeographic ancestries in the Hardy-Weinberg equilibrium analysis. Second, the lack of demonstrable CYBA genotype-phenotype associations in terms of oxidative stress markers compromises the credibility of the observed association between the various polymorphic alleles and the two composite outcomes. Third, we had no access to a replication cohort to validate our findings. Finally, although there is the possibility that the observed associations of individual CYBA gene polymorphisms with outcomes might be the result of $L D$ with other neighboring genetic variants within the locus, our haplotype analysis generated on the $4 C Y B A$ gene polymorphisms provides a potential biological rationale for our results.

In conclusion, the present study helps to unravel the complex nature of how genetic variants in the CYBA gene locus might influence NOX activity and ROS generation, and supports the hypothesis that polymorphisms in the CYBA gene locus may improve the prediction of adverse outcomes in hospitalized AKI patients. Larger validation cohort studies are needed to replicate these findings.

\section{Acknowledgments}

This study was funded by a grant from the National Institutes of Health (DK083428 to Mary C. Perianayagam, PhD). The authors thank Gordon S. Huggins, MD (Molecular Cardiology Research Institute, Tufts Medical Center, Boston, Mass., USA) for providing access to the Applied Biosystems 7900HT fast real-time PCR system (RR023387-01) for genotyping analyses, and Sarah R. Greytak, PhD, for technical assistance. The authors would like to acknowledge the assistance of the UAB-UCSD O'Brien Core Center for Acute Kidney Injury Research (NIH P30 DK079337) for the haplotype analyses.

\section{References}

1 Chertow GM, Burdick E, Honour M, Bonventre JV, Bates DW: Acute kidney injury, mortality, length of stay, and costs in hospitalized patients. J Am Soc Nephrol 2005;16:3365-3370.

2 Liangos O, Wald R, O’Bell JW, Price L, Pereira BJ, Jaber BL: Epidemiology and outcomes of acute renal failure in hospitalized patients: a national survey. Clin J Am Soc Nephrol 2006;1:43-51.

3 Bonventre JV, Weinberg JM: Recent advances in the pathophysiology of ischemic acute renal failure. J Am Soc Nephrol 2003;14:2199-2210.

4 Molitoris BA, Sutton TA: Endothelial injury and dysfunction: role in the extension phase of acute renal failure. Kidney Int 2004;66:496-499.

5 Kusaka J, Koga H, Hagiwara S, Hasegawa A, Kudo K, Noguchi T: Age-dependent responses to renal ischemia-reperfusion injury. J Surg Res 2010, E-pub ahead of print.

6 Tanaka R, Fujita M, Tsuruta R, Fujimoto K, Aki HS, Kumagai K, Aoki T, Kobayashi A, Izumi T, Kasaoka S, Yuasa M, Maekawa T: Urinary trypsin inhibitor suppresses excessive generation of superoxide anion radical, systemic inflammation, oxidative stress, and endothelial injury in endotoxemic rats. Inflamm Res 2010;59:597-606.

7 Kfouri F, de Castro I, Testagrossa L, Delle H, da Silva AM, Bastos AP, Vieira JM Jr, Yu L: Role of p21 and oxidative stress on renal tubular resistance after acute ischaemic injury. Nephrol Dial Transplant 2010;25:1795-1803.

8 Billings FT 4th, Ball SK, Roberts LJ 2nd, Pretorius M: Postoperative acute kidney injury is associated with hemoglobinemia and an enhanced oxidative stress response. Free Radic Biol Med 2011;50:14801487. 


\begin{tabular}{|c|c|}
\hline Nephron Extra 2011;1:112-123 & \\
\hline $\begin{array}{l}\text { DOI: } 10.1159 / 000333017 \\
\text { Published online: October 21, } 2011\end{array}$ & $\begin{array}{l}\text { @) } 2011 \text { S. Karger AG, Basel } \\
\text { www.karger.com/nne }\end{array}$ \\
\hline
\end{tabular}

9 Homsi E, Mota da Silva S Jr, Machado de Brito S, Boucada Inacio Peixoto E, Butori Lopes de Faria J, Janino P: p53-mediated oxidative stress and tubular injury in rats with glycerol-induced acute kidney injury. Am J Nephrol 2011;33:49-59.

10 Jaber BL, Rao M, Guo D, Balakrishnan VS, Perianayagam MC, Freeman RB, Pereira BJ: Cytokine gene promoter polymorphisms and mortality in acute renal failure. Cytokine 2004;25:212-219.

11 Lu JC, Coca SG, Patel UD, Cantley L, Parikh CR: Searching for genes that matter in acute kidney injury: a systematic review. Clin J Am Soc Nephrol 2009;4:1020-1031.

12 Stafford-Smith M, Podgoreanu M, Swaminathan M, Phillips-Bute B, Mathew JP, Hauser EH, Winn MP, Milano C, Nielsen DM, Smith M, Morris R, Newman MF, Schwinn DA: Association of genetic polymorphisms with risk of renal injury after coronary bypass graft surgery. Am J Kidney Dis 2005; 45:519-530.

13 Perianayagam MC, Liangos O, Kolyada AY, Wald R, MacKinnon RW, Li L, Rao M, Balakrishnan VS, Bonventre JV, Pereira BJ, Jaber BL: NADPH oxidase p22phox and catalase gene variants are associated with biomarkers of oxidative stress and adverse outcomes in acute renal failure. J Am Soc Nephrol 2007;18:255-263.

14 du Cheyron D, Fradin S, Ramakers M, Terzi N, Guillotin D, Bouchet B, Daubin C, Charbonneau P: Angiotensin converting enzyme insertion/deletion genetic polymorphism: its impact on renal function in critically ill patients. Crit Care Med 2008;36:3178-3183.

15 Haase-Fielitz A, Haase M, Bellomo R, Lambert G, Matalanis G, Story D, Doolan L, Buxton B, Gutteridge G, Luft FC, Schunck WH, Dragun D: Decreased catecholamine degradation associates with shock and kidney injury after cardiac surgery. J Am Soc Nephrol 2009;20:1393-1403.

16 Popov AF, Hinz J, Schulz EG, Schmitto JD, Wiese CH, Quintel M, Seipelt R, Schoendube FA: The eNOS 786C/T polymorphism in cardiac surgical patients with cardiopulmonary bypass is associated with renal dysfunction. Eur J Cardiothorac Surg 2009;36:651-656.

17 Alam A, O'Connor DT, Perianayagam MC, Kolyada AY, Chen Y, Rao F, Mahata M, Mahata S, Liangos O, Jaber BL: Phenylethanolamine N-methyltransferase gene polymorphisms and adverse outcomes in acute kidney injury. Nephron Clin Pract 2010;114:c253-c259.

18 Popov AF, Schulz EG, Schmitto JD, Coskun KO, Tzvetkov MV, Kazmaier S, Zimmermann J, Schondube FA, Quintel M, Hinz J: Relation between renal dysfunction requiring renal replacement therapy and promoter polymorphism of the erythropoietin gene in cardiac surgery. Artif Organs 2010;34: 961-968.

19 Greene EL, Paller MS: Oxygen free radicals in acute renal failure. Miner Electrolyte Metab 1991;17: $124-132$

20 San José G, Moreno MU, Oliván S, Beloqui O, Fortuño A, Diez J, Zalba G: Functional effect of the p22phox -930A/G polymorphism on p22phox expression and NADPH oxidase activity in hypertension. Hypertension 2004;44:163-169.

21 Guzik TJ, West NE, Black E, McDonald D, Ratnatunga C, Pillai R, Channon KM: Functional effect of the $\mathrm{C} 242 \mathrm{~T}$ polymorphism in the $\mathrm{NAD}(\mathrm{P}) \mathrm{H}$ oxidase p22phox gene on vascular superoxide production in atherosclerosis. Circulation 2000;102:1744-1747.

22 Schirmer M, Hoffmann M, Kaya E, Tzvetkov M, Brockmoller J: Genetic polymorphisms of NAD(P)H oxidase: variation in subunit expression and enzyme activity. Pharmacogenomics J 2008; 8:297-304.

23 Bedard K, Attar H, Bonnefont J, Jaquet V, Borel C, Plastre O, Stasia MJ, Antonarakis SE, Krause KH: Three common polymorphisms in the CYBA gene form a haplotype associated with decreased ROS generation. Hum Mutat 2009;30:1123-1133.

24 Hou SH, Bushinsky DA, Wish JB, Cohen JJ, Harrington JT: Hospital-acquired renal insufficiency: a prospective study. Am J Med 1983;74:243-248.

25 Mehta RL, Kellum JA, Shah SV, Molitoris BA, Ronco C, Warnock DG, Levin A: Acute Kidney Injury Network: report of an initiative to improve outcomes in acute kidney injury. Crit Care 2007;11:R31.

26 Levy MM, Fink MP, Marshall JC, Abraham E, Angus D, Cook D, Cohen J, Opal SM, Vincent JL, Ramsay G: 2001 SCCM/ESICM/ACCP/ATS/SIS International Sepsis Definitions Conference. Crit Care Med 2003;31:1250-1256.

27 Knaus WA, Draper EA, Wagner DP, Zimmerman JE: APACHE II: a severity of disease classification system. Crit Care Med 1985;13:818-829.

28 Knaus WA, Wagner DP: Multiple systems organ failure: epidemiology and prognosis. Crit Care Clin 1989;5:221-232. 
29 Levey AS, Bosch JP, Lewis JB, Greene T, Rogers N, Roth D: A more accurate method to estimate glomerular filtration rate from serum creatinine: a new prediction equation. Modification of Diet in Renal Disease Study Group. Ann Intern Med 1999;130:461-470.

30 Griendling KK, Sorescu D, Ushio-Fukai M: $\mathrm{NAD}(\mathrm{P}) \mathrm{H}$ oxidase: role in cardiovascular biology and disease. Circ Res 2000;86:494-501.

31 Dinauer MC, Pierce EA, Bruns GA, Curnutte JT, Orkin SH: Human neutrophil cytochrome b light chain (p22-phox). Gene structure, chromosomal location, and mutations in cytochrome-negative autosomal recessive chronic granulomatous disease. J Clin Invest 1990;86:1729-1737.

32 Moreno MU, San Jose G, Orbe J, Paramo JA, Beloqui O, Diez J, Zalba G: Preliminary characterisation of the promoter of the human p22(phox) gene: identification of a new polymorphism associated with hypertension. FEBS Lett 2003;542:27-31.

33 Hoffmann M, Schirmer MA, Tzvetkov MV, Kreuz M, Ziepert M, Wojnowski L, Kube D, Pfreundschuh M, Trumper L, Loeffler M, Brockmoller J: A functional polymorphism in the NAD(P)H oxidase subunit CYBA is related to gene expression, enzyme activity, and outcome in non-Hodgkin lymphoma. Cancer Res 2010;70:2328-2338.

34 Inoue N, Kawashima S, Kanazawa K, Yamada S, Akita H, Yokoyama M: Polymorphism of the NADH/ NADPH oxidase p22 phox gene in patients with coronary artery disease. Circulation 1998;97:135137.

35 Goliasch G, Wiesbauer F, Grafl A, Ponweiser E, Blessberger H, Tentzeris I, Wojta J, Schillinger M, Huber K, Maurer G, Mannhalter C, Sunder-Plassmann R: The effect of p22-PHOX (CYBA) polymorphisms on premature coronary artery disease ( $\leq 40$ years of age). Thromb Haemost 2011;105:529534.

36 Hayaishi-Okano R, Yamasaki Y, Kajimoto Y, Sakamoto K, Ohtoshi K, Katakami N, Kawamori D, Miyatsuka T, Hatazaki M, Hazama Y, Hori M: Association of NAD(P)H oxidase p22 phox gene variation with advanced carotid atherosclerosis in Japanese type 2 diabetes. Diabetes Care 2003;26:458463.

37 Doi K, Noiri E, Nakao A, Fujita T, Kobayashi S, Tokunaga K: Haplotype analysis of NAD(P)H oxidase p22 phox polymorphisms in end-stage renal disease. J Hum Genet 2005;50:641-647. 